\title{
LA JUSTICIA EN LOS ESTATUTOS DE AUTONOMIA
}

\author{
POR \\ JOSE ALMAGRO NOSETE \\ Catedrático de Derecho Procesal \\ Facultad de Derecho de la U.N.E. D.
}

\section{PROPOSITO}

Pretendo dar una visión general y sistematizada de los aspectos particulares que ofrece la normación procesal, la organización judicial y el sistema de leyes procesales en los Estatutos de Autonomía, relacionando en lo que sea menester los preceptos autonómicos con los preceptos constitucionales; aunque, hasta la aprobación y publicación de la Ley Orgánica del Poder Judicial, no podrá saberse el contenido concreto de alguna de estas especialidades autonómicas que se remiten a aquel texto, procuraremos sostener criterios, aun a riesgo de que éstos no concuerden luego con la solución legal. De todos modos no aventuraremos hipótesis políticas, sino que nos ceñiremos, en su caso, a la interpretación técnica de los textos. Se utilizará, como primer modelo, el Estatuto de Autonomía del País Vasco, y con referencia al mismo se examinarán las diferencias del Estatuto de Cataluña, sin repetir conceptos o ideas que estén ya señalados en el primero.

\section{II. en el estatuto DE AUtONOMIA DEL PAIS VASCO}

\section{A) Idea general}

El título II del Estatuto se denomina «de los poderes del País Vasco»e incluye en tres capítulos diferenciados al Parlamento Vasco (capítulo I), al Gobierno vasco (capítulo II) y a la Administración de Justicia en el País Vasco (capítulo III). Esta última impostación del equivalente a "poder judicial» está matizada, sin embargo, en el número 1 del artículo 24. Establece este párrafo que «los poderes del País Vasco se ejercerán a través del Parlamento, del Gobierno y de su presidente o «lendakari». Obviamente, estas precisiones aclaran la unidad del poder judicial en todo el Estado español y el carácter exclusivo de la competencia que sobre «Administración de justicia» atribuye el artículo 149 de la Constitución (núm. 5. ) al Estado. 


\section{B) Legislación procesal}

Según el citado artículo de la Constitución, el Estado tiene competencia exclusiva en materia de legislación procesal «sin perjuicio de las necesarias especialidades que en este orden se deriven de las particularidades del derecho sustantivo de las Comunidades autónomas».

El Estatuto vasco establece que la Comunidad autónoma tiene «competencia exclusiva» en materia de «normas procesales y de procedimientos administrativos y económico-administrativos que se deriven de las especialidades del derecho sustantivo y de la organización propia del País Vasco» (art. 10.6).

Se mezclan en este precepto dos cuestiones diferentes:

1. Las normas procesales que afectan al proceso jurisdiccional.

2. Las normas de procedimiento administrativo y de una variante del mismo, el económico-administrativo, que responden a otro fundamento constitucional; concretamente al número 18 del artículo 149 de la Constitución. Prescindiremos, pues, de este segundo aspecto, que hace referencia a la vía administrativa previa al proceso judicial, en su caso.

El establecimiento de estas «exclusividades» cada una dentro de su respectivo ámbito indica con claridad que en materia de legislación procesal se produce un fenómeno de competencias concurrentes.

Dos fuentes legislativas se advierten: 1. La legislación estatal ordinaria y común para todo el territorio nacional. 2. La legislación emanada del Parlamento vasco que fije las especialidades que correspondan, impuestas por la propia naturaleza del derecho sustantivo vasco.

\section{C) Control jurisdiccional de los actos que emanan de los poderes del País Vasco}

Los actos que emanan del poder legislativo y del gobierno o administración vasca se hallan sometidos al control jurisdiccional especial del Tribunal Constitucional o al control jurisdiccional ordinario de los tribunales de lo contencioso-administrativo.

\section{a) Control de constitucionalidad}

Las leyes del Parlamento vasco están sometidas al control de constitucionalidad por el Tribunal Constitucional (art. 38.1); aunque no se diga expresamente, también pueden impugnarse ante el Tribunal Constitucional las disposiciones sin fuerza de ley y las resoluciones de las Comunidades autónomas, con fundamento en lo que dispone el artículo 161.2 de la Constitución. Los artículos 76 y 77 de la Ley Orgánica del Tribunal Constitucional, de 5 de octubre de 1979, así lo establece. Además, conforme a lo previsto en el artículo 150.1 de la Constitución, que establece la posibilidad de delegar com- 
petencias legislativas en el marco de una ley estatal, podrán fijarse modalidades de control sobre estas normas legislativas. A este supuesto alude el artículo 38.2 del Estatuto.

\section{b) Control de legalidad}

Los actos y acuerdos y las normas reglamentarias emanadas de los órganos ejecutivos y administrativos serán recurribles ante la jurisdicción contenciosoadministrativa (art. 38.3).

\section{D) Defensor del Pueblo}

El Estatuto señala que corresponde al País Vasco la creación y organización de un órgano «similar» a la institución del Defensor del Pueblo que contempla el artículo 54 de la Constitución. Esta figura estatutaria deberá regularse mediante ley del Parlamento vasco. Sus funciones (que respetarán las constitucionalmente establecidas para el Defensor del Pueblo) se ejercerán en coordinación con las de aquél, aunque podrán encomendársele otras específicas (art. 15).

El proyecto de ley orgánica sobre la institución del Defensor del Pueblo excluye (art. 14 de dicho proyecto) de la esfera de competencias del mismo el conocimiento de las quejas que se formulen por los ciudadanos en relación con el funcionamiento de la Administración Pública de las Comunidades autónomas en aquellas materias que fuesen de su exclusiva competencia, aunque en todo caso deberá velar por el respeto a los derechos definidos en el título I de la Constitución. Establece, en este orden de ideas, dicho precepto una coordinación entre el Defensor del Pueblo y la institución similar de la Comunidad autónoma.

\section{E) Ministerio Fiscal $y$ derecho de gracia}

El Ministerio Fiscal, según la Constitución (art. 124), ejerce sus funciones por medio de órganos propios, conforme a los principios de unidad de actuación y dependencia jerárquica y con sujeción a los principios de legalidad e imparcialidad. Responde su organización y funcionamiento a una función unitaria del Estado. El Estatuto se limita a reconocer que tanto los aspectos organizativos como funcionales corresponden íntegramente al Estado, de conformidad con las leyes. Igualmente competencia excluyente corresponde al Estado en cuanto al derecho de gracia (art. 13).

\section{F) Participación ciudadana}

El apartado 3 del artículo 34 contiene la siguiente disposición: «En la Comunidad autónoma se facilitará el ejercicio de la acción popular y la parti- 
cipación en la administración de justicia, mediante la institución del jurado, en la forma y con respecto a aquellos procesos penales que la ley procesal determine.» En realidad, la eficacia de este precepto resulta muy limitada, en atención a los factores de interpretación sistemática que habrán de tenerse en cuenta, pues la regulación, en definitiva, del proceso penal corresponde al Estado. La «facilitación» del ejercicio debe referirse a la creación de las condiciones necesarias para que estas actuaciones no puedan verse turbadas en cuanto a su ejecución y desarrollo.

\section{G) Organización de la justicia}

\section{a) Previsiones constitucionales}

1. El Tribunal Superior de Justicia.-El artículo 152.1 de la Constitución establece que «un Tribunal Superior de Justicia, sin perjuicio de la jurisdicción que corresponde al Tribunal Supremo, culminará la organización judicial en el ámbito territorial de la Comunidad autónoma».

El precedente histórico de este Tribunal habría que encontrarlo en el «Tribunal Superior Vasco», que creó el Estatuto del País Vasco de 4 de octubre de 1936 (art. 3..$^{\circ}$. Según dicho precepto, este Tribunal tenía jurisdicción propia en las materias civiles y administrativas cuya legislación exclusiva correspondiera al País Vasco, conociendo de los recursos de casación y revisión que sobre tales materias se interpusieron.

2. Intervención en las demarcaciones judiciales.-Autoriza la Constitución en el mismo precepto formas de participación de las Comunidades autónomas en la organización de las demarcaciones judiciales del territorio, de conformidad con lo que disponga la Ley Orgánica del Poder Judicial y con respecto a la unidad e independencia de este Poder.

3. Agotamiento de las instancias en el territorio autónomo.-Es ésta, a mi juicio, una de las disposiciones constitucionales más importantes. Tras su formulación técnica laten sanos criterios de política legislativa. Se pretende el acercamiento del Tribunal al justiciable, en cierto modo, como manifestación del principio de «juez natural». Las sucesivas instancias procesales - dice el mencionado precepto- se agotarán ante órganos judiciales radicados en el mismo territorio de la Comunidad autónoma en que esté el órgano competente en primera instancia. Este precepto no merma las funciones del Tribunal Supremo, con jurisdicción en toda España.

\section{b) Desarrollo estatutario}

1. Respecto del Tribunal Superior de Justicia del País Vasco.-Matiza el Estatuto algunos aspectos del Tribunal Superior de Justicia que se «estructurará de acuerdo con lo previsto en la Ley Orgánica del Poder Judicial» (artículo 34.1, incluido en el capítulo III «de la Administración de Justicia en el País Vasco» del título II). El presidente del Tribunal Superior de Justicia del País Vasco será nombrado por el Rey (art. 34.2). 
En cuanto a sus funciones el Tribunal se convierte en el máximo órgano de apelación de la Comunidad autónoma y asume las competencias propias de los recursos de casación y revisión, relativos a las materias propias del derecho civil foral del País Vasco. Las funciones del tribunal de apelaciones parecen desprenderse del inciso establecido en el artículo 34.1, al decir que ante el mismo se agotarán las sucesivas instancias procesales. Y las de casación y revisión específicas resultan de las competencias que señala el artículo 14 en relación con su carácter de máximo órgano judicial del territorio. En tal sentido, deberá tener también atribuciones para resolver como superior jerárquico las cuestiones de competencia que se susciten entre los órganos judiciales del País Vasco.

Orgánicamente será probable que integre en su seno la recientemente creada Audiencia Territorial de Bilbao.

2. Respecto de la intervención en las demarcaciones judiciales.-Esta intervención se limita a la ordenación de las demarcaciones judiciales de ámbito inferior al provincial, con atribuciones para delimitar las respectivas demarcaciones y localizar la capitalidad o cabeza de partido en un determinado lugar de la demarcación (art. 34.1).

3. Respecto del agotamiento de las instancias.-Sólo indica el Estatuto el órgano máximo ante el que se agotan, según señalamos antes. Al fijar en el artículo 14 las que llama el Estatuto «competencias» desarrolla esta previsión que consideramos en el apartado siguiente.

\section{H) Atribuciones de los órganos jurisdiccionales en el País Vasco}

Distingue el artículo 14 las atribuciones según los distintos órdenes judiciales.

\section{a) En el orden civil}

Los Juzgados y Tribunales sitos en el País Vasco tendrán atribuciones para que ante los mismos se desarrollen todas las instancias y grados, incluidos los recursos de casación y revisión en las materias de derecho civil foral propio del País Vasco. Lógicamente de estos recursos de casación y de revisión conocerá el Tribunal Superior de Justicia.

Los recursos de casación y revisión civiles sobre materias de derecho civil común o derecho privado en general (derecho mercantil también) corresponden al conocimiento del Tribunal Supremo. Debe tenerse presente que el derecho procesal civil rige el principio de prorrogación de la competencia territorial, conforme al cual la sumisión expresa o tácita de las partes a cualquier juez que tenga competencia objetiva para entender o conocer del asunto, determina válidamente aquélla. Las atribuciones que se señalan en este punto a la Comunidad autónoma vasca no motivan, pues, a mi entender, competencias objetivas inderogables por la voluntad de las partes si se tiene en cuenta, según ya vimos, que la legislación procesal común corresponde exclusivamente al Estado. Este punto está fuera de dudas respecto de los asuntos que versen 
sobre materias de derecho privado general o común. Sin embargo, es dudoso en cuanto al derecho civil foral propio del País Vasco, pues el Tribunal Superior tiene atribuciones para decidir los recursos de casación y de revisión y el Parlamento vasco tiene competencia legislativa para dictar disposiciones procesales que se deriven de las especialidades del derecho sustantivo vasco. El tratamiento en estos casos de la sumisión de las partes requerirá una mayor profundización para establecer si es preciso que se produzcan o existan unos «puntos de conexión» con el sistema jurídico general.

Análogas consideraciones pueden hacerse respecto de los recursos sobre calificación de documentos referentes al derecho privativo vasco que deban tener acceso al Registro de la Propiedad (apartado c, art. 14). Constituye esta especificación del Estatuto una manifestación del derecho propio en sus aspectos de constancia documental. La calificación de documentos que realizan los registradores de la Propiedad motiva, caso de disconformidad, el agotamiento de la vía gubernativa ante la Dirección General de los Registros y del Notariado. Este precepto excluye esta vía gubernativa. Puede optarse por suprimir la misma o por canalizarla a través de las propias autoridades judiciales de la Comunidad autónoma por vía de recurso gubernativo.

Las controversias que surjan sobre calificación de los mismos deberán atribuirse en último grado al Tribunal Superior de Justicia.

\section{b) En el orden penal}

La competencia se extiende a todas las instancias y grados, excepto los recursos de casación y revisión de los que conocerán el Tribunal Supremo (artículo 14.b). Este precepto tiene, a mi juicio, máxima importancia por las disquisiciones teóricas a que dará lugar y por la trascendencia práctica del mismo. Significa lisa y llanamente que de todos los delitos cometidos en el territorio de la Comunidad autónoma vasca conocerán los jueces y tribunales radicados en el mismo. Si en la causa criminal una vez fallada se interpusiera recurso de casación penal o de revisión penal conocería de éstos la Sala de lo penal del Tribunal Supremo.

En la práctica no debieran plantearse demasiadas cuestiones, pues la interpretación teórica parece en principio sencilla. Pero no es así. Uno de los problemas más graves del Estado español y de nuestra sociedad son los delitos de terrorismo. En función de estos delitos se crearon jurisdicciones especiales y se mantienen jueces y tribunales que excluyen, en realidad, la aplicación del principio reconocido en el precepto del Estatuto. Por supuesto que este tratamiento afecta por igual a todos los delitos de la misma naturaleza cometidos en territorio español. Mas la cuestión es la de saber si este precepto quiere decir algo o no significa nada. Suponemos que se pretenderá sea «un globo pinchado». Con independencia de la significación que se le atribuya mantenemos que la subsistencia de los Juzgados Centrales y de la Audiencia Nacional (con este o con otro nombre) gravita sobre la constitucionalidad del principio de «juez natural», reconocido en el artículo 24 de la Constitución. 


\section{c) En el orden social}

Se repiten los mismos conceptos. El fuero general territorial viene determinado en esta materia por el lugar de prestación de los servicios o por el domicilio del empleador. Las instancias se agotarán en el territorio de la Comunidad autónoma; en consecuencia, las atribuciones que la ley tiene conferidas al Tribunal Central de Trabajo para conocer del recurso de suplicación deben suprimirse. En cambio, los recursos de casación y el de revisión cuando procedan se plantearán ante el Tribunal Supremo.

\section{d) En el orden contencioso-administrativo}

El precepto parte de una distinción entre actos administrativos procedentes de la administración autonómica y actos administrativos procedentes de la administración del Estado. Los primeros deben ser actos dictados por la administración autónoma, dentro de las materias cuya legislación exclusiva le corresponda. Debería regularse lo que ocurra cuando precisamente lo que se discuta sea sobre si el acto es o no adecuado conforme a estas competencias. En alguno de los proyectos de la Ley Orgánica del Poder Judicial está previsto un recurso ante el Tribunal Supremo contra las sentencias del Tribunal Superior de Justicia si se actúa con exceso de jurisdicción. Parece que éste podría ser, junto a otros posibles ejemplos, un caso amparable por dicho recurso. Y ello con independencia de otros remedios, cuales serían la cuestión de inconstitucionalidad o el recurso de amparo constitucional en su caso.

Los segundos son actos de la administración del Estado en cualquiera de sus manifestaciones, ya territorial, ya institucional.

La impugnación en vía contencioso-administrativa de los actos de la administración de la Comunidad autónoma debe agotarse ante el Tribunal Superior de Justicia; en cambio, de la impugnación de los otros casos sólo conocen los órganos jurisdiccionales, radicados en la Comunidad autónoma, en primera instancia (art. 14.e).

\section{e) Decisión de conflictos}

Las cuestiones de competencia que surjan entre los órganos judiciales del País Vasco deben resolverse conforme a las reglas generales, es decir, por el órgano judicial superior común e inmediato a ambos. En último extremo, cuando éstos no tengan un superior común debe resolver el conflicto el Tribunal Superior de Justicia. Así debe entenderse, por interpretación sistemática, de acuerdo con las reglas en vigor, el alcance del apartado d) del artículo 14. Las cuestiones de competencia que surjan entre órganos judiciales radicados en el País Vasco y otros del Estado radicados fuera de la Comunidad autónoma deberán ser resueltos por el Tribunal Supremo.

En realidad, los conflictos de jurisdicciones, es decir, entre tribunales ordinarios y especiales, no pueden tener el mismo sentido en el futuro, dado el mandato constitucional sobre unidad de jurisdicciones. Sí se podrán plantear cuestiones conflictivas entre órganos judiciales pertenecientes a distintos ór- 
denes judiciales, pero el tratamiento de estas cuestiones en orden a su resolución será análogo al previsto para las cuestiones de competencia.

\section{I) Fuero especial de los miembros del Parlamento vasco en materia penal}

Los miembros del Parlamento vasco gozan de un fuero especial en relación con el enjuiciamiento de los posibles delitos que cometan durante su mandato, dentro del territorio de la Comunidad autónoma. La instrucción y juicio que integre el proceso penal correspondiente se atribuyen al conocimiento del Tribunal Superior de Justicia, a quien incumbe adoptar como es lógico las medidas cautelares que procedan. No podrán adoptarse respecto de los mismos medidas preventivas de detención o retención, salvo en caso de flagrante delito.

Igualmente, gozan de fuero especial respecto de los delitos que cometan fuera del territorio de la Comunidad autónoma; en estos casos, la responsabilidad penal será exigible ante la Sala de lo penal del Tribunal Supremo (artículo 26.6).

\section{J) Policía judicial}

El Estatuto asigna al Gobierno del País Vasco el mando y organización de la policía autónoma. Esta policía estará inicialmente constituida por el Cuerpo de Miñones y Miqueletes dependientes de las Diputaciones de Vizcaya y Guipúzcoa que se restablecen (art. 17). Cuando esta policía funcione como «policía judicial» estará al servicio y actuará con dependencia de la Administración de Justicia, según lo que dispongan las leyes procesales (art. 36). Esta misma dependencia se señala también en otro precepto (art. 17.3).

\section{K) Personal judicial}

El sistema de nombramientos y régimen de provisión de plazas del personal judicial y personal al servicio de la justicia está en función de lo que dispongan la Ley Orgánica del Poder Judicial y la ley del Consejo General del Poder Judicial y de las atribuciones que se reserve respecto de éstos el Gobierno del Estado español, pues estas atribuciones las asume el gobierno del País Vasco.

En ambos casos será mérito preferente para acceder a la provisión de estas plazas el conocimiento del euskera y de las instituciones del derecho foral vasco. No podrán establecerse excepciones o méritos preferenciales por razón de naturaleza o de vecindad en lo que se refiere a magistrados, jueces y secretarios.

Los concursos y oposiciones para cubrir las plazas judiciales y secretariales se convocarán, a instancia de la Comunidad autónoma, según lo que disponga la Ley Orgánica del Poder Judicial. En caso de que estas plazas queden vacantes, prové a su cobertura el Tribunal Superior de Justicia de acuerdo con las normas que contenga la citada Ley Orgánica (art. 35). 


\section{ESTATUTO DE AUTONOMIA DE CATALUÑA}

\section{A) Analogías}

El Estatuto de Cataluña ofrece en las materias que hemos examinado redacciones más simplificadas, aunque en los grandes aspectos sustancialmente coincidentes. Regula las siguientes materias: Competencia legislativa en materia procesal (art. 9.3); policía judicial (art. 13); asunción por la Generalidad de las funciones que se atribuyan al Gobierno del Estado por las leyes orgánicas del poder judicial (art. 18); Tribunal Superior de Justicia (art. 19); competencia de los órganos jurisdiccionales en Cataluña (art. 20); nombramiento del presidente del Tribunal y de los jueces, magistrados y secretarios (art. 21); convocatoria de concursos y oposiciones (art. 22); méritos preferentes (art. 23); Defensor del Pueblo (art. 35), y control de la Generalidad (art. 40).

\section{B) Diferencias}

A diferencia del Estatuto vasco, que habla de los «poderes» del País Vasco y contempla las tres manifestaciones clásicas (aunque matiza: «De la Administración de Justicia en el País Vasco") incurriendo a veces en reiteraciones, el Estatuto catalán regula la materia relativa a la Administración de Justicia en el título I y reserva el título II, que versa sobre la Generalidad, para tratar de los diferentes capítulos los órganos genuinos de la misma (Parlamento, presidente y Consejo ejecutivo o Gobierno) y el control de la Generalidad.

Matiza algunos aspectos propios. Así, en relación con la Administración de Justicia, señala que corresponde a la Generalidad coadyuvar en la organización de los tribunales consuetudinarios y tradicionales (art. 18.3) y especifica que la actual Audiencia Territorial de Barcelona se integrará en el Tribunal Superior de Cataluña.

Omite, a diferencia del Estatuto vasco, la preferencia como mérito del conocimiento de la lengua catalana, y considera sólo como tal la especialización en derecho catalán (art. 23).

La institución equivalente al Defensor del Pueblo de la Comunidad autónoma recibe un nombre propio: «Sindic de Greuges» (Síndico de agravios) (artículo 35).

Finalmente, se instituye un control preventivo de constitucionalidad interna para dictaminar sobre la adecuación al Estatuto de los proyectos de leyes que se sometan a debate y aprobación del Parlamento de Cataluña (art. 41). 


\section{LAS ATRIBUCIONES EN MATERIA PENAL DE LA AUDIENCIA NACIONAL EN RELACION CON LA CONSTITUCION Y LOS ESTATUTOS}

\section{A) Apunte bistórico}

La historia de este tema es la siguiente. El artículo 14 de la Ley de Enjuiciamiento Criminal establece como fuero principal para la atribución territorial del conocimiento de los delitos el del lugar de la comisión del mismo. Siempre, no obstante, se han mantenido fueros reservados, explicables en razón del cargo público desempeñado por la persona o por cualquier otra razón de aforamiento.

En España la represión judicial de los delitos de bandidaje y terrorismo se ha vinculado en muchas ocasiones a la jurisdicción militar. El Decreto de 21 de septiembre de 1960 refundió las disposiciones sobre rebelión militar y bandidaje y terrorismo (núm. 1.794/60) y mantuvo la competencia de la jurisdicción militar para conocer de los delitos que establecía, que eran juzgados por procedimiento sumarísimo. Por ley de 2 de diciembre de 1963 se creó un Juzgado y un Tribunal de Orden Público, con jurisdicción en todo el territorio nacional y con una competencia material muy amplia (art. $3 .^{\circ}$ ) a las que se unían las que resultaran por inhibición, en su caso, de la jurisdicción militar, cuando de acuerdo con lo que disponía el Decreto anterior entendiera esta jurisdicción que los hechos no revestían «gravedad o características adecuadas para ser calificados con arreglo a esta disposición».

Quedó derogado en virtud de esta ley el artículo 2. ${ }^{\circ}$ del Decreto antes mencionado que establecía la competencia primaria de la jurisdicción militar para entender de los delitos que se definían. Por Decreto-ley de 16 de agosto de 1968 se restableció la vigencia del artículo $2 .^{\circ}$ del Decreto de 21 de noviembre de 1960, derogado por la ley de 2 de diciembre de 1963, y se atribuyó de nuevo competencia a la jurisdicción militar, sin perjuicio de las facultades de inhibición a favor de la jurisdicción ordinaria ${ }^{1}$.

Dos leyes de 15 de noviembre de 1971 (núms. 42 y 44) reforman el Código Penal y el Código de Justicia Militar. La ley 44/71 derogó los dos Decretos citados y los artículos $10^{\circ}$ y $2 .^{\circ}$ de la ley creadora de la jurisdicción de orden público; se depuraron tipos penales, se produjeron consecuencias de tipo procesal, tales como que no siempre determinadas conductas daban lugar a enjuiciamientos por consejo de guerra sumarísimo, sino que cabría también el consejo de guerra ordinario y se suprimía el carácter único de la pena de muerte. En conjunto, la reforma se valoró positivamente.

Doctrinalmente, los profesores de Derecho procesal urgían en las reuniones que anualmente celebraban el pleno restablecimiento de la unidad jurisdiccional; el Colegio de Abogados de Madrid pedía a los poderes públicos la supresión del Juzgado y Tribunal de Orden Público (año 1969) y el Congreso Nacional de la Abogacía (año 1970) adoptó entre sus conclusiones una petición en análogo sentido.

${ }^{1}$ Cfr. José Almagro Nosete, Protección procesal de los derechos humanos en España, en «Revista de Derecho Procesal Iberoamericana», enero-marzo 1973, pág. 32. 
$\mathrm{El}$ autor de este trabajo, en una ponencia presentada al V Congreso Internacional de Derecho procesal, celebrado en Méjico (año 1972), estudiaba y exponía las razones por las que debían limitarse las atribuciones de la jurisdicción militar a delitos específicamente militares y aclaraba los criterios doctrinales por los que resultaba imposible admitir la calificación de órgano de la jurisdicción ordinaria que se daba en el preámbulo de la ley creadora a la jurisdicción de orden público.

Las demandas doctrinales sobre reconocimiento del principio de unidad de jurisdicciones y la necesidad de reducir las hipertrofiadas funciones judiciales atribuídas a la jurisdicción militar, motivaron que se gestara la idea, durante el régimen político anterior de crear un tribunal y unos órganos judiciales centrales que permitieran la supresión del Tribunal de Orden Público y de su Juzgado, así como la reducción de aquellas funciones. Se trataba, pues, de institucionalizar una jurisdicción de excepción por medio de arreglos legales que permitieran sustraer los delitos de terrorismo del conocimiento de los jueces a quienes corresponderían si se derogaba la legislación especial.

Entre las denominaciones aplicables a dicho órgano central se manejó en algunos anteproyectos la de Audiencia Nacional. Dicho organismo judicial asumiría funciones de distintos órdenes judiciales. Prevaleció la denominación de Tribunal Central de lo penal (para mantener al Tribunal Central de Trabajo, junto a los que se creaba un Tribunal Central de lo contencioso-administrativo); este Tribunal previsto en la derogada Ley de Base Orgánica de la Justicia (ley $42 / 74$ de 28 de noviembre), tenía amplias competencias centralizadoras de jurisdicciones especiales, como la de delitos monetarios y orden público y extensivas a delitos cuya razón de atribución se hacía depender de criterios indeterminados, aunque, en ocasiones, para justificar la exclusión del fuero natural (lugar de la comisión del delito) se hablaba de «perjuicio patrimonial a una generalidad de personas en territorios de distintas Audiencias provinciales» o productores de efecto en lugares pertenecientes a distintas Audiencias provinciales.

Igualmente, se modificaba el criterio de juez legal o natural, trastrocando el sentido de los preceptos de la Ley de Enjuiciamiento Criminal que se refieren al nombramiento de juez instructor especial (arts. 303, 304 y 305) que afectan a la fase de instrucción nunca a la de enjuiciamiento propiamente dicho, pues estos preceptos respetan al juez natural (Audiencia provincial) a quien corresponde el conocimiento de la causa, según las reglas del artículo 18 de la Ley de Enjuiciamiento Criminal. Obsérvese que no es lo mismo juez instructor (la instrucción, de suyo, no tiene que estar necesariamente confiada a un órgano judicial, aunque sí deben depender del mismo la adopción de medidas cautelares sobre la persona y los bienes) que juez decisor o auténtico juez.

Este trastrueque se producía mediante la atribución a la Sala de Gobierno del Tribunal Supremo de facultades para encomendar la instrucción de determinados delitos a los Juzgados Centrales, con atribución automática de la competencia para conocer al Tribunal Central (art. 35 de la Ley de Bases derogada).

Bajo capa de una pretendida unidad de jurisdicciones que enfáticamente se consideraba como una de las «directrices de las bases» (II) se intentaba la «nor- 
malización» de la situación judicial con algunos retoques, pero dejando subsistentes los principios políticos inspiradores del sistema.

Vengo manteniendo que cuando se habla de unidad de jurisdicciones no se aspira a lograr una abstracta función unitaria de la justicia, radicada en el poder estatal, sino la consecución para todos los campos de la justicialidad de las garantías que habitualmente conlleva la jurisdicción ordinaria. Entre estas garantías ocupa principal relieve la garantía de juez natural o legal.

Pendiente de desarrollo la Ley de Bases se producen el Decreto-ley de 26 de agosto de 1975 sobre terrorismo y normas para la prevención y enjuiciamiento de delitos, que establece nuevas tipificaciones y el Decreto-ley de 18 de febrero de 1976, sobre terrorismo que revisa el anterior y regula la competencia para el enjuiciamiento de delitos.

\section{B) Situación actual}

Instaurada la Monarquía en España y todavía, dentro de una fase de transición política, en tanto se elabora una nueva Constitución que aprueben los españoles, se dicta el Real Decreto-ley de 4 de enero de 1977 por el que se crea la Audiencia Nacional ${ }^{2}$; con la misma fecha se dictan otros dos Reales Decretos-leyes, uno por el que se suprimen el Tribunal y los Juzgados de Orden Público y se crean en Madrid dos nuevos Juzgados de Instrucción y otro sobre competencia jurisdiccional en materia de terrorismo.

Las circunstancias en que la nueva legislación se produce hacen augurar a algunos un positivo cambio de rumbo en materia de protección de derechos humanos, respecto de la plena vigencia de garantías procesales y judiciales, definido, como propósito, más que como realidad, puesto que las limitaciones que imponen la legislación en vigor, las enrevesadas disposiciones orgánicas de carácter reglamentario, que atiendan a la provisión de cargos judiciales y la ausencia de una ley fundamental que regule el nuevo sistema político en ciernes, no permiten considerar este primer paso como satisfactorio en cuanto a la plenitud de aquellas garantías.

La Audiencia Nacional, resucita una de las ideas (según hemos visto), establecida en los proyectos de la derogada Ley de Bases Orgánica de la Justicia, luego configurada como tres Tribunales Centrales adscritos a órdenes judiciales diferentes. Pese al énfasis del preámbulo de la Ley reguladora de la Audiencia Nacional, las competencias que se le señalan están, prácticamente, transcritas del artículo 35 de la derogada Ley de Bases de la Justicia, con una excepción, la de los delitos de terrorismo, incluídos en el número $4 .^{\circ}$ de dicho artículo...; no obstante, por Real Decreto-ley del mismo día, en una dispersión de textos legislativos sin precedentes, «se estima llegado el momento de dejar sin efecto aquellas competencias que en materia de terrorismo permanecen atribuídas a la jurisdicción militar» y se atribuye «la instrucción, conocimiento

2 Cfr. Alberto Montón Redondo, La Audiencia Nacional, los Juzgados Centrales de Instrucción y su competencia objetiva en materia penal, en «Revista de Derecho Procesal Iberoamericana», núm. 2, 1979, pág. 341. 
y fallo de las causas por los delitos de terrorismo» a los «Juzgados Centrales de Instrucción y a la Audiencia Nacional» sin más excepciones que las que resulten de la aplicación de los artículos 9. y 13 del Código de Justicia Militar.

Todavía el mismo día otro Real Decreto-ley suprime la jurisdicción de orden público y declara «que la instrucción, conocimiento y fallo de las causas por los delitos que venían atribuídos a los órganos judiciales que se suprimen se atribuirán en lo sucesivo a los Juzgados y Tribunales a que correspondan conforme a las normas de competencia de la Ley de Enjuiciamiento Criminal».

Sólo con una paciencia «benedictina» le es dable al intérprete seguir los entresijos y vericuetos de nuestra legislación en materia de tanta importancia. Pienso que estas dificultades se proyectan sobre los justiciables y sobre quienes técnicamente tienen que asistirlos.

Al mismo tiempo, en el Real Decreto-ley sobre competencia judicial en materia de terrorismo, se estaban atribuyendo en materia de las que conocía en parte el Tribunal suprimido al órgano recién creado (art. $1 .^{\circ}$ ), cuya entrada en funcionamiento se prevenía para el 15 de febrero de 1977 con sus correspondientes Juzgados Centrales. Simultáneamente los Juzgados «ordinarios» de instrucción números 21 y 22 , creados por el Real Decreto-ley que deroga el Tribunal y los Juzgados de Orden Público se hacen cargo de la tramitación de los procedimientos, que en estos Juzgados se llevaban, «conforme a las normas procesales aplicables en la fecha de su incoación».

En resumen, la nueva y compleja regulación procesal en esta materia, con independencia de que mejore las condiciones de provisión de los cargos judiciales, mediatizadas, sin embargo, por las normas reglamentarias anteriores, no restituía a sus fueros generales el enjuiciamiento de los delitos, sino que hacía pervivir con nuevos nombres y modalidades ( $\mathrm{y}$ por supuesto con la eliminación de algunos tipos delictivos no concordes con la nueva situación política), una jurisdicción centralizada en materia penal, junto a otras que no son de considerar en esta oportunidad.

Con razón, al comentar el Real Decreto-ley sobre creación de la Audiencia Nacional en cuanto a atribuciones penales ha podido decir el profesor PrietoCastro: «Se observa cómo el Real Decreto-ley entrega a apreciaciones subjetivas e imprecisas la determinación de las atribuciones y la competencia del nuevo órgano, con evidente riesgo del juez legal o natural.» Este atentado al principio de juez legal o natural es doble. Por una parte, porque hace depender la competencia para conocer de determinados delitos de estas apreciaciones subjetivas. De otra, porque sustrae al conocimiento de sus jueces naturales a quienes delincan según la naturaleza del delito ${ }^{3}$.

Desde la perspectiva del tiempo y aprobada la nueva Constitución se puede esperar que se pretenda realizar por el actual régimen democrático, la misma operación jurídica que se adivinaba tras los proyectos y leyes del régimen anterior. A saber, dar «carta de naturaleza», como órgano «normal» de la jurisdicción «ordinaria», a un órgano judicial centralizado en materia penal que

${ }^{3}$ Cfr. Leonardo Prieto-Castro y Ferrándiz, Tribunales españoles, organización y funcionamiento, Madrid, 1979, pág. 51. 
rompa el tradicional principio del forum delicti commissi, todavía vigente en la vieja Ley de Enjuiciamiento Criminal.

La fortuna de esta fórmula que comienza a tener tanto más arraigo cuanto más «nominalísticamente» se interprete la Constitución depende de que sigan prosperando disposiciones como las que más adelante comentaremos.

En efecto, la vigente Constitución establece en el artículo 24.2 que todos tienen derecho al juez ordinario predeterminado por la ley. Se constitucionaliza pues, la garantía de juez legal o natural; es decir, del juez preconstituido y establecido legalmente que asegura un juicio imparcial al que se llega por medio del proceso debido. Excluye, pues, los jueces ad boc o ex post facto. La Constitución de Alemania Federal reconoce esta garantía, bajo la fórmula «nadie puede ser sustraído a su juez legal» (art. 101). Y la italiana señala que «nadie puede ser sustraído al juez natural preconstituido por ley» (art. 25).

Los temas de interpretación constitucional se pueden analizar en relación con las categorías que Karl Loewenstein ${ }^{4}$ ha establecido al realizar la clasificación «ontológica» de las Constituciones. Conforme a estas categorías se contrasta el texto constitucional con la realidad del proceso político y los actos de los detentadores del poder. Se denomina Constitución normativa a la que efectivamente se aplica como limitación del poder; Constitución «nominal», a la que pese a la buena voluntad de los detentadores del poder es en gran parte una aspiración o expectativa, no llevada a la práctica por incidencias y dificultades del proceso político; y Constitución «semántica» a la que se limita a cubrir formalmente a los detentadores del poder.

Considero que estamos en la fase de Constitución nominal pero no podemos acercarnos a la fase de Constitución semántica. Se llega a ésta cuando se comienza a incurrir en fenómenos de perversión de la Constitución, mediante el manejo de las formalidades legales, sin tocar fondo o evitando los contenidos reales de las normas constitucionales. Por ejemplo, se respeta formalmente el principio de legalidad en materia penal si se establecen tipos delictivos previos a la comisión de unos hechos. Pero no se respeta materialmente si los tipos penales están concebidos de tal suerte que la elasticidad de los mismos burla el fin que pretende asegurar el principio de legalidad. Igualmente, se respeta en la forma el principio de juez preconstituido si se establece por ley qué órganos deben conocer de determinados hechos; no se respeta, materialmente y se incurre en su contrario el juez ex post facto, si la determinación del órgano que debe juzgar depende de apreciaciones subjetivas, interpuestas aunque sea por norma, entre la definición delictiva y la atribución de la competencia. $\mathrm{O}$ si, establecidos legalmente unos criterios generales sobre la atribución de las competencias, determinadas categorías de delitos se extraen de esta regla para seguir criterios competenciales diversos.

Actualmente, este desvío se observa en la trayectoria seguida por la legislación que contemplamos. Durante el régimen anterior no hubo en su primera etapa, rubor en reconocer el carácter especial de determinadas jurisdicciones; posteriormente se emplearon perversiones del lenguaje jurídico como fue la de denominar jurisdicción ordinaria a la jurisdicción de orden público, más tarde

4 Karl Loewenstein, Teoría de la Constitución, Barcelona, 1970, pág. 199. 
se proyectó sin restitución del enjuiciamiento a sus competencias naturales, normalizar el órgano enjuiciador, mediante el nonnato Tribunal Central de lo penal. $Y$ en el tránsito de cambio de régimen, antes de promulgarse la nueva Constitución se crean, con plena apariencia de normalidad unos órganos con competencias penales, embebidas en otras de otros órdenes judiciales, con el propósito de transformar en normales u ordinarias unas reglas de competencia trastrocadas por jurisdicciones especiales. Esta es la realidad.

A poco tiempo de promulgada la Contitución las Cortes aprueban la ley $56 / 1976$ de 4 de diciembre, sobre medidas especiales en relación con los delitos de terrorismo. Ciñéndonos estrictamente al punto que comentamos (sin entrar en otras presuntas inconstitucionalidades), la citada ley reafirma en el artículo $5 .^{\circ}$ la competencia de la Audiencia Nacional y de los Juzgados Centrales para la instrucción y conocimiento de estos delitos.

Cuando estaba a punto de expirar la vigencia de dicha ley se dicta el Real Decreto-ley de 23 de noviembre de 1979, que amplía las competencias de la Audiencia Nacional en materia penal. Este Real Decreto-ley fue convalidado por el Congreso de los Diputados por un sólo voto ante la grave duda que plantea su constitucionalidad.

Con referencia al tema concreto que examinamos, lo más grave son las anticipaciones que el Real Decreto-ley hace sobre la Audiencia Nacional, en un intento de configurar en el futuro sus atribuciones en materia penal como normales. En el preámbulo ya anuncia «que la competencia de la Audiencia Nacional es objeto de especial consideración en el proyecto de Ley Orgánica del Poder Judicial remitido a las Cortes Generales». Y en el artículo 3. ${ }^{\circ}$ reitera el mismo concepto: lo dispuesto en el artículo $10^{\circ}$ «quedará sin efecto cuando entre en vigor la futura Ley Orgánica y se determine por ley la específica competencia de la Sala de lo penal de la Audiencia Nacional».

No sabemos cómo se pueden conciliar estas atribuciones en materia penal con lo que previenen los artículos 24.2 y apartado 1 del artículo 152 de la Constitución. $\mathrm{Ya}$ hemos dicho de qué manera interpretamos el artículo 24. Fijémonos en el último precepto constitucional citado que está recogido en sendos preceptos de los Estatutos de autonomía: ¿Qué quiere decir que las instancias se agoten en el territorio de la Comunidad autónoma? ¿Acaso que sólo aquellas instancias que por ley se atribuyan? Para ésto, no hubiera hecho falta el precepto constitucional. Si el precepto significa algo, sólo puede querer decir que todos los delitos que se cometan en el territorio autónomo serán enjuiciados por órganos radicados en dicho territorio, sin perjuicio de las atribuciones del Tribunal Supremo. 